\title{
Research
}

Trevor Lambert, Raph Goldacre, Fay Smith and Michael J Goldacre

\section{Reasons why doctors choose or reject careers in general practice:}

\author{
national surveys
}

\begin{abstract}
\section{Background}

Less than one-third of newly qualified doctors in the UK want a career in general practice. The English Department of Health expects that half of all newly qualified doctors will become GPs.
\end{abstract}

\section{Aim}

To report on the reasons why doctors choose or reject careers in general practice, comparing intending GPs with doctors who chose hospital careers.

\section{Design and setting}

Questionnaire surveys in all UK medical graduates in selected qualification years.

\section{Method}

Questions about specialty career intentions and motivations, put to the qualifiers of 1993, 1996, 1999, 2000, 2002, 2005, 2008, and 2009, 1 year after qualification, and at longer time intervals thereafter.

\section{Results}

'Enthusiasm for and commitment to the specialty' was a very important determinant of choice for intending doctors, regardless of chosen specialty. 'Hours and working conditions' were a strong influence for intending GPs lcited as having had 'a great deal' of influence by $75 \%$ of intending GPs in the first year after qualification), much more so than for doctors who wanted a hospital career (cited by 30\%). Relatively few doctors had actually considered general practice seriously but then rejected it: $78 \%$ of the doctors who rejected general practice gave "job content" as their reason, compared with $32 \%$ of doctors who rejected other specialties.

\section{Conclusion}

The shortfall of doctors wanting a career in general practice is not accounted for by doctors considering and rejecting it. Many do not consider it at all. There are very distinctive factors that influence choice for, and rejection of, general practice.

\section{Keywords}

career choice; general practice; medical education; workforce, medical.

\section{INTRODUCTION}

Up to 10000 GPs in the UK may retire over the next 5 years and this will contribute to a shortfall of practising GPs. ${ }^{1-3}$ Additionally, it has been difficult to recruit doctors to general practice in adequate numbers, ${ }^{4,5}$ as is also the case for some other specialties such as psychiatry and emergency medicine. The English Department of Health has set a target that at least half of specialty training posts in medicine should be in general practice. ${ }^{6}$ Other countries, too, have difficulty in recruiting enough GPs. ${ }^{7-11}$

This article reports on some of the factors that influence junior doctors' choice for a career in general practice in the UK. It also reports on reasons why some junior doctors gave serious consideration to a career in general practice but then decided against it.

\section{METHOD}

For many years, the UK Medical Careers Research Group has undertaken surveys of all newly qualified doctors from all UK medical schools in selected year-ofqualification years. Questionnaires were sent at specific years after graduation lat year 1, 3, 5, and longer time intervals thereafter) to all UK medical graduates in selected years of qualification between 1974 and 2009. The methods have been described in detail elsewhere. ${ }^{12,13}$ Nonresponders received several reminders. Each cohort comprised all UK graduates from that year. The General Medical Council provided addresses, and this information was updated regularly by the responders.

TW Lambert, MSc, statistician; R Goldacre $B A$, research assistant; F Smith, PhD, research officer; MJ Goldacre, FFPH, FRCP, professor of public health, UK Medical Careers Research Group, Department of Public Health, University of Oxford, Oxford.

\section{Address for correspondence}

Trevor Lambert, Unit of Health-Care

Epidemiology, Department of Public Health,

University of Oxford, Rosemary Rue Building, Old
The paper reports on the qualifiers of 1993, 1996, 1999, 2000, 2002, 2005, 2008, and 2009. In their first year after qualification, graduates were asked 'What is your choice of long-term career?', and were asked to give their chosen specialty lor, if applicable, their non-medical career choice). All graduates, except those of 2005 and 2009 , were also asked to indicate whether each factor from a list of 11 had influenced their choice of specialty 'not at all', 'a little', or 'a great deal'. The graduates of 2009 were given a subset of four of the 11 factors. Three years after qualification, a followup questionnaire was sent to each of the graduates of 1993, 1996, and 2002, asking them again to specify their choices of career and the factors influencing their decision. A further follow-up questionnaire was sent 5 years post-qualification to the graduates of 1993, 1996, 1999, 2000, and 2002.

The doctors who qualified in 2002, 2005, and 2008 were also asked 1 year after graduation: 'Is there a choice of long-term career which you have seriously considered but have now decided not to pursue? If they answered yes, they were asked 'What was that choice?' and 'What are your most important reasons for rejecting that choice?' This was an open-ended question to which some responders provided one reason for rejection and others gave several reasons. A coding scheme was developed, which reflected the main themes within the answers. Two coders independently categorised each reason into a theme. Any differences between coders were resolved through discussion. Reasons for rejection

Road Campus, Oxford, OX7 3LF

E-mail: trevor.lambertadph.ox.ac.uk

Submitted: 7 June 2012; Editor's response: 26 June 2012; final acceptance: 11 July 2012. (c)British Journal of General Practice

This is the full-length article (published online 26 Nov 2012) of an abridged version published in print. Cite this article as: Br J Gen Pract 2012; DOI: 10.3399/bjgp12X659330 


\section{How this fits in}

The NHS needs about $50 \%$ of medical school graduates to become GPs, but a much smaller percentage of doctors leave medical school wanting careers as GPs. Lifestyle factors are important determinants of a positive choice for a career in general practice. So, too, is enthusiasm for general practice. Some doctors are put off general practice because of their view of its job content.

given by doctors who had considered and rejected general practice were compared with reasons given by doctors who had rejected other clinical specialties.

Standard summary statistics and confidence intervals are reported. To test statistical significance, Mann-Whitney $U$ tests and $\chi^{2}$ statistics (reporting Yates's continuity correction where there was only one degree of freedom, and MantelHaenszel linear-by-linear $\chi^{2}$ test for linear association between two variables) were used.

\section{RESULTS}

\section{Response}

One year after graduation, surveys containing questions about career choice and factors affecting career choice, were

\section{Table 1. Doctors who specified each factor as influencing their choice of long-term career a great deal: graduates of 1993, 1996, 1999, 2000, 2002,2008 , and 2009}

\begin{tabular}{|c|c|c|c|c|c|c|}
\hline \multirow[b]{2}{*}{ Influencing factor } & \multicolumn{2}{|c|}{ Year 1, \% } & \multicolumn{2}{|c|}{ Year 3, \% } & \multicolumn{2}{|c|}{ Year $5, \%$} \\
\hline & $\begin{array}{c}\text { GP } \\
n=5675\end{array}$ & $\begin{array}{c}\text { Hospital } \\
n=13800\end{array}$ & $\begin{array}{c}\text { GP } \\
n=2361\end{array}$ & $\begin{array}{l}\text { Hospital } \\
n=5294\end{array}$ & $\begin{array}{c}\text { GP } \\
n=4419\end{array}$ & $\begin{array}{l}\text { Hospital } \\
n=8132\end{array}$ \\
\hline Domestic circumstances & $49.2^{\mathrm{a}}$ & $16.0^{\mathrm{e}}$ & $48.7^{\mathrm{b}}$ & $15.8^{e}$ & $68.5^{\mathrm{a}}$ & $27.7^{e}$ \\
\hline Hours/working conditions & $75.4^{a}$ & $30.4^{e}$ & $81.6^{a}$ & $35.7^{\mathrm{e}}$ & $87.7^{\mathrm{a}}$ & $41.5^{e}$ \\
\hline Eventual financial prospects & $15.0^{\mathrm{a}}$ & $11.8^{\mathrm{e}}$ & $22.8^{\mathrm{a}}$ & $11.1^{\mathrm{e}}$ & $17.7^{\mathrm{a}}$ & $9.4^{e}$ \\
\hline Promotion/career prospects & $16.2^{\mathrm{a}}$ & $24.3^{e}$ & $22.8^{\mathrm{a}}$ & $24.8^{h}$ & $20.7^{\mathrm{a}}$ & $25.1^{\mathrm{e}}$ \\
\hline Self-appraisal of own skills/aptitudes & $47.8^{b}$ & $50.4 f$ & $50.0^{d}$ & $51.1^{\mathrm{h}}$ & $52.6^{b}$ & $59.3^{e}$ \\
\hline Advice from others & $15.5^{d}$ & $16.6 \mathrm{~h}$ & $16.6^{d}$ & $17.2^{\mathrm{h}}$ & $11.5^{d}$ & $15.0^{\mathrm{e}}$ \\
\hline Student experience of subject & $38.3^{\mathrm{d}}$ & $48.7^{\mathrm{e}}$ & $20.8^{d}$ & $27.7^{\mathrm{e}}$ & $19.8^{d}$ & $25.3^{e}$ \\
\hline Particular teacher/department & $13.2^{\mathrm{d}}$ & $32.1^{\mathrm{e}}$ & $11.3^{\mathrm{d}}$ & $32.3^{h}$ & $5.9^{d}$ & $29.1^{e}$ \\
\hline Inclinations before medical school & $15.1^{\mathrm{d}}$ & $14.3 \mathrm{~h}$ & $14.8^{\mathrm{d}}$ & $12.6^{9}$ & $13.0^{\mathrm{b}}$ & $10.1^{\mathrm{e}}$ \\
\hline Experience of jobs so far & $46.8^{b}$ & $53.5^{e}$ & $54.2^{b}$ & $69.7^{\mathrm{e}}$ & $53.2^{\mathrm{b}}$ & $71.9^{e}$ \\
\hline Enthusiasm/commitment & $63.2^{\mathrm{a}}$ & $73.3^{e}$ & $56.5^{d}$ & $67.2^{\mathrm{e}}$ & $63.2^{\mathrm{a}}$ & $80.3^{e}$ \\
\hline
\end{tabular}

Year 1 includes the cohorts of 1993, 1996, 1999,2000,2002, 2008, and 2009; year 3 includes the cohorts of 1993, 1996, and 2002; year 5 includes the cohorts of 1993, 1996, 1999, 2000, and 2002. Significant differences between males and females within the group that chose general practice are denoted as follows: ${ }^{\mathrm{a}} \mathrm{P}<0.001 .{ }^{b} \mathrm{P}<0.01$ ${ }^{c} \mathrm{P}<0.05 .{ }^{d}$ Not significant. Significant differences between hospital practice and general practice within each year are denoted as follows: ${ }^{\mathrm{P}}<0.001 .{ }^{f} 0.001<\mathrm{P}<0.01 .{ }^{g} 0.01<\mathrm{P}<0.05 .{ }^{h} \mathrm{P} \geq 0.05$. sent to 33986 doctors from seven cohorts (the graduates of 1993, 1996, 1999, 2000, 2002, 2008, and 2009). A total of 20250 (60\%) replied. Three years after qualification, a follow-up survey containing the same questions was sent to 11975 UK doctors from three cohorts (the graduates of 1993 1996, 2002): 8246 (69\%) replied. Five years after qualification, a further follow-up survey containing the same questions was sent to 20626 doctors from five cohorts (graduates of 1993, 1996, 1999, 2000, 2002): $13166(64 \%)$ replied

\section{Choices for general practice}

The data from all doctors from these cohorts who gave a first preference for a career in general practice or a hospital specialty were analysed. Combining cohorts, in the first year after qualification (in which seven cohorts were surveyed), $29 \%$ of responders expressed a preference for general practice (5675 doctors specified general practice as their first choice, and 13800 specified one of the hospital specialties); in the third year after qualification (in which three cohorts were surveyed), $31 \%$ specified general practice 2361 chose general practice, 5294 the hospital specialties); and in the fifth year after qualification (five cohorts surveyed), the corresponding figures were 35\% (4419 and 8132). Many doctors who do not initially opt for a career in general practice do so after a few years and, as few intending GPs switch from general practice to other specialties, the percentage of doctors who want a career in general practice increases with increasing time from qualification.

\section{Factors influencing career choice}

Considering factors that influenced doctors choice of specialty 'a great deal', in year 1 , $63 \%$ of intending GPs and $73 \%$ of intending hospital doctors specified 'enthusiasm for and commitment to the specialty' (Table 1). The corresponding figures in year 3 were $57 \%$ and $67 \%$; and those in year 5 were $63 \%$ and $80 \%$. Considerations of hours and working conditions' had a great deal of influence on $75 \%$ of intending GPs and $30 \%$ of the doctors who wanted a hospital career in year 1, 82\% for GPs and 36\% for intending hospital doctors in year 3 , and $88 \%$ and $42 \%$ in year 5 . Thus not only is there a difference between intending GPs and intending hospital doctors in relation to the influence of hours and working conditions on their career choice, but also the influence of hours and working conditions on career choice becomes more important for both intending GPs and hospital doctors as the post-qualification 


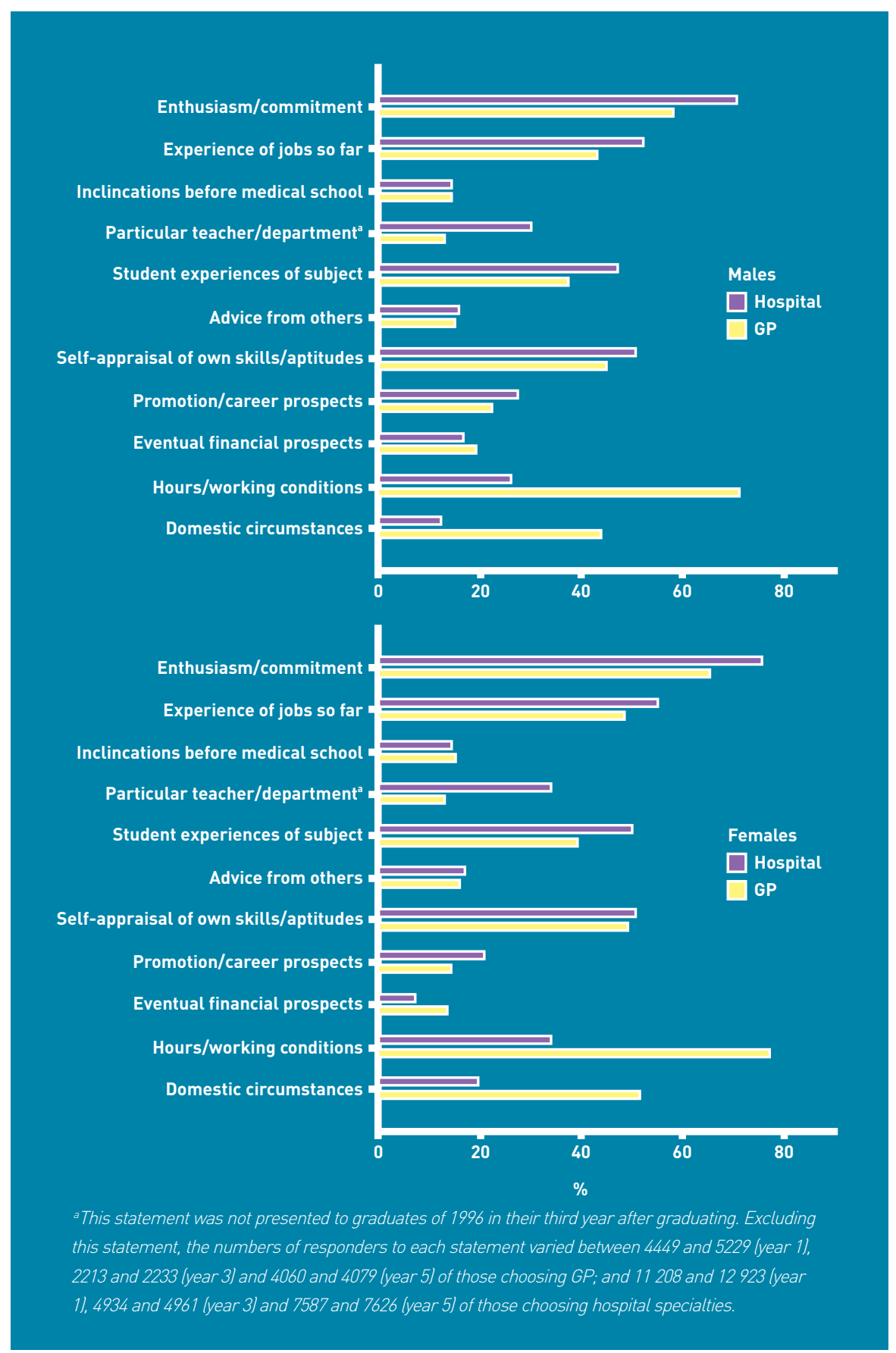

Figure 1. Percentage of doctors who specified each factor as influencing their choice of longterm career a great deal in year 1: graduates of 1993, 1996, 1999, 2000, 2002, 2008, and 2009. other factors is shown in Table 1

Comparisons between males and females, as well as between doctors who chose general practice or the hospital specialties, in factors influencing career choice 1 year after qualification are shown in Figure 1. Of the female doctors who chose general practice 1 year after qualification, $77 \%$ of the intending GPs rated hours/ working conditions' as having influenced their choice a great deal, compared with $34 \%$ of females intending to be hospital doctors. 'Domestic circumstances' were rated as very important by $51 \%$ of the intending female GPs, compared with 19\% of females intending to be hospital doctors $\left(\chi^{2}\right.$ tests, $\left.P<0.001\right)$. Males who intended to be GPs were also much more influenced by 'hours/working conditions' than those who intended to be hospital doctors (71\% compared with $26 \%$ ) and by domestic circumstances' ( $44 \%$ compared with $12 \%$ ), both $P<0.001$.

At both 3 and 5 years after graduation, 'hours/working conditions' was still rated as the most influential factor in deciding upon a career in general practice, and this factor had more influence on females than males $(P<0.001)$.

The data were re-analysed separately for the cohorts of 1993-2002 and 2008-2009, to see whether any important differences emerged when comparing later with earlier qualifiers (Figure 2), using data gathered 1 year after qualification. Of the females who chose general practice, $78 \%$ of the 2008-2009 graduates rated domestic circumstances' as having influenced their choice a great deal, compared with 39\% of 1993-2002 graduates ( $\chi^{2}$ tests, $\left.P<0.001\right)$. The corresponding figures for males were $67 \%$ in the 2008-2009 cohorts, up from 35\% in the earlier cohorts. Other differences are shown in Figure 2.

\section{Doctors who considered general practice} as a career and then decided not to pursue it

Questionnaires were sent to the qualifiers of 2002, 2005, or 2008, 1 year after their graduation, asking them if there was a specialty that they had seriously considered but decided not to pursue. The proportions of responders who specified such a specialty were $29 \%$ (797/2778) of the qualifiers of $2002,27 \%(843 / 3128)$ of 2005 qualifiers, and 29\% (933/3249) of 2008 qualifiers. After excluding statements that could not be coded, and doctors whose switches of specialty were within the same broader specialty group, 14 there were 2267 responders (811 males, 1456 females) who 


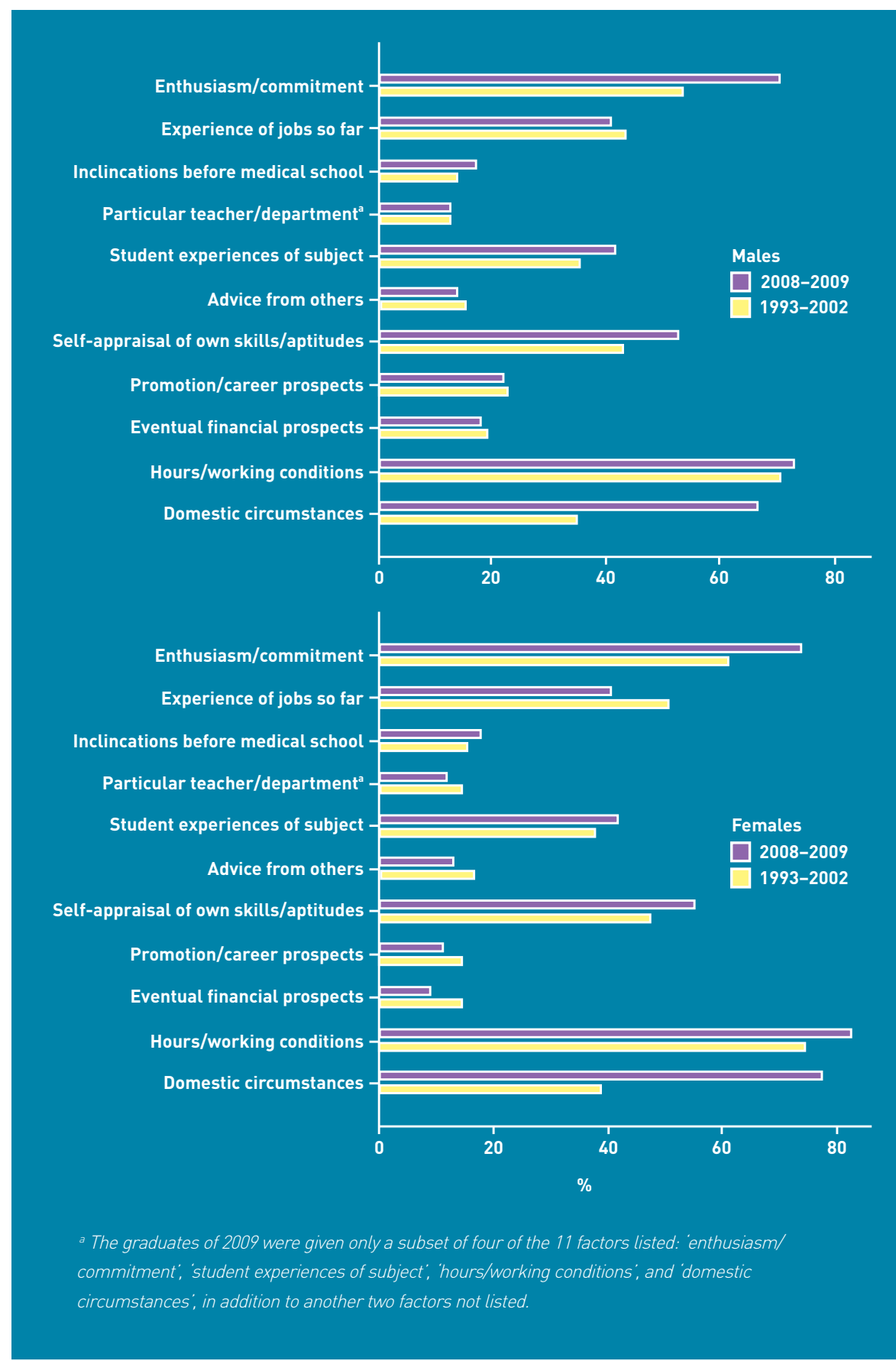

Figure 2. Percentages of doctors who specified each factor as influencing their choice of longterm career a great deal in year 1: 1993-2002 and 2008-2009 graduates compared by sex. had considered and rejected a specialty and who gave at least one classifiable reason for doing so $(25 \%$ of the total number of responders).

Only 5.6\% (127/2267) of these responders specified that they had considered and rejected general practice $13.8 \%$ of males, $6.6 \%$ of females). There was no significant upward or downward trend across the cohorts in the percentage that considered and rejected general practice: it was 5.5\% in the 2002 cohort, $5.5 \%$ in the 2005 cohort, and $5.8 \%$ in the 2008 cohort.
Reasons for rejecting general practice, after having seriously considered it as a career

The reasons given by the 127 doctors who rejected general practice were compared with those given by the 2140 doctors who rejected all other specialties combined. Statements that were classified as job content' were given by $78 \%$ of the doctors who rejected general practice and by $32 \%$ of doctors who rejected other specialties (Table 2). Some of the categories in Table 2 contain very small numbers and percentages for general practice but are included so that factors that have influenced rejection of hospital specialties can be seen. Doctors who rejected general practice were the most likely of all doctors rejecting a specialty to cite 'job content' as their reason for doing so. Illustrative examples of such statements about general practice (quoted as written by the doctors) were 'too dull and monotonous', not practically challenging', 'too many "social" patients', 'I found it lonely/isolating'. Other illustrative comments on job content, precisely as written, are reproduced in Box 1.

Doctors who rejected general practice were also significantly more likely to mention too much paperwork and administrative work (mentioned by $7 \%$ of doctors rejecting GP, compared with $1 \%$ of doctors who rejected all other specialties; $P<0.001)$. All other reasons lincluding competition for posts, training, and working relationships) were mentioned by very small numbers of the doctors who rejected general practice. 'Work-life balance' was the most frequently mentioned reason given by those rejecting specialties other than general practice (43\%), but was mentioned by only one of the 127 doctors who rejected general practice.

\section{Choosing general practice, following rejection of another specialty}

Of the doctors who had considered and rejected a specialty other than general practice, 30.4\% (690/2267) subsequently chose general practice, making general practice the most popular choice among those who had rejected an alternative. This is similar to the percentage of doctors overall (27\%), who, from the same cohorts, chose general practice as their first preference in their first post-qualification year. ${ }^{14}$ Doctors who rejected a specialty for reasons related to work-life balance, stressful working conditions, length of training, or competition were more likely to favour general practice over other specialties, whereas doctors who rejected a specialty for reasons related to job content 
Table 2. Distribution of doctors' reasons ${ }^{\text {a }}$ for rejecting general practice and all other specialties combined, comparing males and females

\begin{tabular}{|c|c|c|c|c|c|c|}
\hline \multirow[b]{2}{*}{ Reason for rejecting specialty } & \multicolumn{2}{|c|}{ All, \% } & \multicolumn{2}{|c|}{ Male, \% } & \multicolumn{2}{|c|}{ Female, \% } \\
\hline & GP & All other & GP & All other & GP & All other \\
\hline Job content & 78.0 & 32.4 & 71.0 & 38.3 & 80.2 & 29.0 \\
\hline Content of rejected specialty & 33.1 & 11.0 & 29.0 & 14.0 & 34.4 & 9.3 \\
\hline Positive preference for another specialty & 29.1 & 10.3 & 25.8 & 12.2 & 30.2 & 9.3 \\
\hline Bad experience of the rejected specialty & 11.0 & 11.5 & 9.7 & 12.4 & 11.5 & 11.0 \\
\hline Too much administration/ bureaucracy & 7.1 & 0.8 & 6.5 & 1.3 & 7.3 & 0.6 \\
\hline Work-life balance & 0.8 & 42.6 & 0.0 & 29.4 & 1.0 & 50.2 \\
\hline Training & 5.5 & 8.2 & 0.0 & 11.7 & 7.3 & 6.3 \\
\hline Poor training & 4.7 & 7.4 & 0.0 & 11.0 & 6.3 & 5.3 \\
\hline Too much requirement for research & 0.8 & 1.1 & 0.0 & 1.3 & 1.0 & 1.0 \\
\hline Competition & 3.1 & 12.7 & 6.5 & 14.1 & 2.1 & 11.9 \\
\hline Competitive specialty & 3.1 & 7.4 & 6.5 & 8.3 & 2.1 & 6.9 \\
\hline Too few training posts/competition for training posts & 0.0 & 5.0 & 0.0 & 5.3 & 0.0 & 4.9 \\
\hline Exams - too many/too difficult & 0.0 & 1.2 & 0.0 & 1.4 & 0.0 & 1.0 \\
\hline Stressful/lack of support/working conditions & 6.3 & 10.5 & 9.7 & 11.8 & 5.2 & 9.7 \\
\hline Training too long & 0.8 & 5.4 & 0.0 & 5.6 & 1.0 & 5.2 \\
\hline Future of the specialty uncertain/unstable & 7.1 & 1.7 & 6.5 & 3.2 & 7.3 & 0.8 \\
\hline Inadequate salary & 0.0 & 1.3 & 0.0 & 2.3 & 0.0 & 0.7 \\
\hline Self-appraisal & 3.9 & 4.5 & 3.2 & 4.7 & 4.2 & 4.4 \\
\hline Advice & 2.4 & 1.4 & 0.0 & 1.5 & 3.1 & 1.3 \\
\hline Working relationships within the specialty & 0.8 & 5.3 & 3.2 & 5.5 & 0.0 & 5.2 \\
\hline Fear of litigation & 0.8 & 2.5 & 0.0 & 1.4 & 1.0 & 3.1 \\
\hline Change in personal circumstances & 0.0 & 1.6 & 0.0 & 0.8 & 0.0 & 2.1 \\
\hline Lack of exposure and opportunities so far & 1.6 & 2.1 & 3.2 & 1.9 & 1.0 & 2.2 \\
\hline Number of doctors rejecting specialty & 127 & 2140 & 31 & 780 & 96 & 1360 \\
\hline $\begin{array}{l}\text { aSome doctors gave more than one reason and each rea } \\
\text { rejecting general practice and those rejecting other spec } \\
\left(\chi^{2} 1=85.5, P<0.001\right) \text {, training }\left(\chi^{2} 1=0.8, P=0.36\right) \text {, compe }\end{array}$ & etiti & counted. & gnific & tests, c & $\begin{array}{l}\text { Daring } \\
\text { work- } \\
1=0.6\end{array}$ & $\begin{array}{l}\text { hose } \\
\text { fe balance } \\
P=0.931\end{array}$ \\
\hline
\end{tabular}

were less likely to favour general practice over other specialties (Table 3).

\section{DISCUSSION}

\section{Summary}

Distinctive factors that influence doctors towards a career in general practice, besides enthusiasm for the specialty, include their expectations about working hours and working conditions, and considerations of their domestic circumstances. These factors - their preferences for a way of life - were particularly important for females but were also important for many of the male doctors who chose general practice. They also seem to have become increasingly important for the most recently qualified doctors.

The percentage of doctors who seriously considered but then rejected general practice is quite small. Given that somewhere between one-quarter and onethird of all doctors choose general practice, it is striking that only about 1 in 20 who considered but then rejected a specialty did so for general practice. By contrast, the surgical specialties were the chosen career preference of $20 \%$ of responders (32\% of males, $12 \%$ of females); and, of all who considered but decided not to pursue a specialty, 32\% considered but decided not to pursue surgery (37\% of males, $29 \%$ of females ${ }^{14}$. Many doctors simply do not consider general practice as a career option in the first place. Of those who do, but who later decide against it, the overwhelming reasons are to do with their perceptions of job content. Reasons for considering and rejecting other specialties have been reported elsewhere. ${ }^{14}$

\section{Strengths and limitations}

The strengths are that the surveys are large scale, have spanned many years, are confidential, and are undertaken by a team that is independent of organisations that might inhibit responders from giving honest answers. Response rates are good for this type of study. However, non-responder bias 


\section{Box 1. Sample job content comments about changing choice from general practice, showing sex (male, female), year of qualification, and new career preference}

\section{Content of rejected specialty}

- ' 'Lack of acute problems.' (female, 2002, hospital medicine)

- Was choosing it for lifestyle reasons but don't find it interesting.' (female, 2002, paediatrics)

- 'Too dull and monotonous. Not practically challenging. Too many "social" patients.' (male, 2002, surgery)

- I would like to know a lot about one specialty in depth than a little surface knowledge of everything in medicine.' 'female, 2005, obstetrics and gynaecologyl

- No acute medicine. Lifestyle too relaxing.' (female, 2005, hospital medicine)

- 'Patients not taking responsibility for their own health and the wish to blame doctor for their health problems.' (female, 2005, obstetrics and gynaecology)

- "I feel that I would be drifting into it for the "lifestyle" choice. I would like the variety but not such managing chronic conditions.' (female, 2008, emergency medicine)

- 'The lifestyle appeals to me but I find general practice very slow and extremely boring. '(female, 2008, hospital medicine

- Lonely specialty.' (female, 2008, anaesthetics)

- 'I did not find it challenging, exciting or enjoyable. I found it lonely/isolating.' (f, 2008, hospital medicine)

Positive preference for another specialty

- Enthusiasm for acute care.' (female, 2002, surgery)

- Found / enjoyed hospital medicine much more as a PRHO [pre-registration house officer] than I had expected to.' (female, 2002, anaesthetics)

- 'I like psychiatry more than I like GP.' (male, 2005, psychiatry)

- An overwhelming passion for paediatrics! Reasons for doing GP lincluding working hours, a familyfriendly career path) were not strong enough to convince me [that I should do general practice]' (female, 2008, paediatrics)

\section{Bad experience of the rejected specialty}

- 'Did not enjoy medical school GP placement.' (male, 2005, hospital medicine)

- ' ' no longer want to deal with every single issue - emotional, physical, mental, social for all my patients and then still get slagged by patients for not doing a good job. '(female, 2008, hospital medicine)

\section{Too much administration/bureaucracy}

- 'Pressures on time keeping, that is, only 5-10 mins for each patient.' (female, 2002, hospital medicine)

- Do not like financial/running a business aspects.' (female, 2002, hospital medicine)

- All the targets being introduced for GPs and advice on healthy lifestyle etc. Not using medical training. (female, 2005, obstetrics and gynaecology)

- Not wishing to be involved in running a business and probably providing only 9-5 Mon-Fri care.' 'female, 2005, hospital medicine)

is possible, as with all voluntary surveys.

\section{Comparison with existing literature}

Reasons for choosing general practice reported in other UK studies include the challenging variety of work, continuity of care and the one-to-one patient relationship work-life balance, and compatibility with family life. ${ }^{15-17}$ This study also found that doctors who chose general practice attached importance to their enthusiasm for the work, working hours, working conditions, and their own domestic circumstances (the study did not ask specifically about variety of work or continuity of care). A study in Switzerland found that doctors who chose primary care tended to be less careeroriented and placed more importance on life outside work. Two studies in Canada found doctors who chose general practice were more likely than others to be older and in a long-term relationship at the time when they made their choice, ${ }^{18}$ or to enter family medicine in preference to hospital medicine in order to have higher earning potential early in their careers. ${ }^{19}$

Implications for practice and research

The careers that doctors eventually pursue are determined, collectively, by a balance between their career preferences and the availability of training posts and career opportunities. Medical school intakes in the UK have expanded considerably in recent years, and there are restrictions on the numbers of training and career posts in hospital specialties. It seems likely that, even more in the future than has been the case in the past, doctors who initially hope for a career in a hospital specialty will eventually work in general practice. The present findings relating to year 1 preferences must substantially reflect the aspirations of junior doctors when they leave medical school and soon after. It is imperative that medical schools manage medical students expectations about likely future needs for hospital specialists and GPs. 


\section{Table 3. Percentage distribution of chosen specialties, by reasons for having rejected an alternative specialty}

\begin{tabular}{|c|c|c|c|c|c|c|c|c|c|}
\hline \multirow[b]{2}{*}{ Chosen specialty } & \multicolumn{9}{|c|}{ Reason for rejection } \\
\hline & $\begin{array}{l}\text { Work-life } \\
\text { balance }\end{array}$ & $\begin{array}{c}\text { Job } \\
\text { content }\end{array}$ & $\begin{array}{l}\text { Competition } \\
\text { and exams }\end{array}$ & $\begin{array}{c}\text { Stressful } \\
\text { environment/ } \\
\text { working } \\
\text { conditions }\end{array}$ & $\begin{array}{c}\text { Training } \\
\text { content } \\
\text { and quality }\end{array}$ & $\begin{array}{l}\text { Training } \\
\text { too long }\end{array}$ & $\begin{array}{l}\text { Lack of } \\
\text { exposure } \\
\text { so far }\end{array}$ & $\begin{array}{c}\text { Career } \\
\text { development/ } \\
\text { career } \\
\text { stability }\end{array}$ & $\begin{array}{c}\text { Inadequate } \\
\text { salary }\end{array}$ \\
\hline Medical specialties & 16.6 & 21.9 & 17.8 & 13.2 & 14.2 & 16.4 & 29.8 & 26.7 & 17.9 \\
\hline Paediatrics & 3.8 & 6.2 & 2.9 & 8.1 & 6.0 & 4.3 & 6.4 & 2.2 & 0 \\
\hline Surgery & 5.0 & 19.4 & 7.2 & 11.1 & 6.0 & 0 & 6.4 & 11.1 & 17.9 \\
\hline Obstetrics and gynaecology & 2.4 & 4.7 & 3.3 & 3.8 & 3.3 & 0.9 & 4.3 & 0 & 3.6 \\
\hline Anaesthetics & 11.2 & 14.6 & 9.4 & 12.0 & 21.9 & 9.5 & 8.5 & 4.4 & 10.7 \\
\hline Radiology & 3.4 & 1.8 & 6.2 & 2.6 & 3.8 & 5.2 & 2.1 & 11.1 & 7.1 \\
\hline Clinical oncology & 1.5 & 1.3 & 0.7 & 1.7 & 2.2 & 1.7 & 2.1 & 4.4 & 3.6 \\
\hline Pathology & 1.9 & 2.4 & 3.3 & 3.8 & 2.7 & 0.9 & 0 & 2.2 & 3.6 \\
\hline General practice & 44.4 & 16.0 & 35.9 & 32.5 & 26.8 & 50.9 & 25.5 & 24.4 & 25.0 \\
\hline Community medicine & 0.3 & 0.1 & 0 & 0 & 0 & 0 & 0 & 0 & 0 \\
\hline Public health & 0.9 & 1.3 & 0.4 & 0 & 1.6 & 2.6 & 2.1 & 0 & 0 \\
\hline Other medical specialties & 0.7 & 0.5 & 0.7 & 0.9 & 1.6 & 0 & 0 & 2.2 & 0 \\
\hline Non-medical careers & 0.5 & 0.8 & 2.2 & 1.7 & 1.6 & 3.4 & 4.3 & 6.7 & 3.6 \\
\hline Total (n) & 913 & 793 & 276 & 234 & 183 & 116 & 47 & 45 & 28 \\
\hline
\end{tabular}

\section{Funding}

This is an independent report commissioned and funded by the Policy Research Programme in the Department of Health (reference 016/0116). The views expressed are not necessarily those of the Department.

\section{Ethical approval}

This study was approved by the National Research Ethics Service, following referral to the Brighton and Mid-Sussex Research Ethics Committee in its role as a multicentre research ethics committee (ref 04/Q1907/48).

\section{Provenance}

Freely submitted; externally peer reviewed.

\section{Competing interests}

The authors have declared no competing interests.

\section{Acknowledgements}

We would like to thank Emma Ayres for administering the surveys, Janet Justice and Alison Stockford for data entry, and Louise Laxton for programming support. We are very grateful to all the doctors who participated in the surveys.

\section{Discuss this article}

Contribute and read comments about this article on the Discussion Forum: http://www.rcgp.org.uk/bjgp-discuss
The fact that, for many, choices for general practice are heavily influenced by considerations of lifestyle is expected but nonetheless very important. It seems that lifestyle considerations are becoming more important, as evidenced in responses from the most recent cohorts, which may reflect a more general shift in young people's societal attitudes.

Some responders said that they turned away from general practice because they considered it to be too concerned with minor ailments, chronic illness, and 'social' content. These were minority views that may also be misconceptions about the realities of modern general practice; and, in any case, the social dimensions of medicine, continuing care of chronic disease, and the satisfaction of successfully dealing with minor ailments are elements of general practice that particularly attract many doctors to it. Nonetheless, important work could be done to investigate how to increase the appeal of general practice to doctors who have not yet been drawn to it. 


\section{REFERENCES}

1. Deloitte Centre for Health Solutions. Primary care: today and tomorrow improving general practice by working differently. London: Deloitte, 2012.

2. Health and Social Care Information Centre. NHS medical and dental staff, 2001-2011: detailed results tables. http://www.ic.nhs.uk/statistics-and-datacollections/workforce/nhs-staff-numbers/nhs-staff-2001--2011-medicaland-dental (accessed 22 Oct 2012).

3. British Medical Association. National survey of GP opinion 2011. London: British Medical Association, 2011.

4. Lambert T, Goldacre M. Trends in doctors' early career choices for general practice in the UK: longitudinal questionnaire surveys. Br J Gen Pract 2011; DOI: 10.3399/bjgp11X583173.

5. Jones L, Fisher T. Workforce trends in general practice in the UK: results from a longitudinal study of doctors' careers. Br J Gen Pract 2006; 56(523): 134-136.

6. Department of Health. A high quality workforce: NHS Next Stage review. London: Department of Health, 2008.

7. Buddeberg-Fischer B, Klaghofer R, Stamm M, et al. Primary care in Switzerland - no longer attractive for young physicians? Swiss Med Wkly 2006; 136(27-28): 416-424.

8. Bethune C, Hansen PA, Deacon D, et al. Family medicine as a career option: how students' attitudes changed during medical school. Can Fam Physician 2007; 53(5): 880-885.

9. Biggs WS, Schmittling GT, Bieck AD, et al. Entry of US medical school graduates into family medicine residencies: 2010-2011 and 3-year summary. Fam Med 2011; 43(9): 625-630.
10. Walker HK. Primary care is dying in the United States: mutatis mutandis. Med Educ 2006; 40(1): 9-11.

11. Kentikelenis A, Papanicolas I. Economic crisis, austerity and the Greek public health system. Eur J Public Health 2012; 22(1): 4-5.

12. Lambert TW, Goldacre MJ, Edwards C, Parkhouse J. Career preferences of doctors who qualified in the United Kingdom in 1993 compared with those of doctors qualifying in 1974, 1977, 1980, and 1983. BMJ 1996; 313(7048): 19-24.

13. Goldacre MJ, Davidson JM, Lambert TW. Career choices at the end of the pre-registration year of doctors who qualified in the United Kingdom in 1996. Med Educ 1999; 33(12): 882-889.

14. Goldacre MJ, Goldacre R, Lambert TW. Doctors who considered but did not pursue specific clinical specialties as careers: questionnaire surveys. J R Soc Med 2012; 105(4): 166-176

15. Irish B, Lake J. When and why do doctors decide to become general practitioners? Implications for recruitment into UK general practice specialty training. Educ Prim Care 2011;22(1):20-4.

16. Watson J, Humphrey A, Peters-Klimm F, Hamilton W. Motivation and satisfaction in GP training: a UK cross-sectional survey. Br J Gen Pract 2011;61(591):e645-9.

17. Lloyd JR, Leese B. Career intentions and preferences of GP registrars in Yorkshire. Br J Gen Pract 2006;56(525):280-2.

18. Scott I, Gowans M, Wright B, et al. Determinants of choosing a career in family medicine. CMAJ 2011;183(1):E1-E8.

19. Vanasse A, Orzanco MG, Courteau J, Scott S. Attractiveness of family medicine for medical students: influence of research and debt. Can Fam Physician 2011;57(6):e216-27. 